\title{
Phenotypic screening identifies a new oxazolone inhibitor of necroptosis and neuroinflammation
}

\author{
Sara R. Oliveira (1) ', Pedro A. Dionísio ${ }^{1}$, Hugo Brito ${ }^{1}$, Lídia Franco ${ }^{1}$, Catarina A. B. Rodrigues ${ }^{1}$, Rita C. Guedes ${ }^{1}$,
} Carlos A. M. Afonso', Joana D. Amaral' ${ }^{1}$ and Cecília M. P. Rodrigues ${ }^{1}$

\begin{abstract}
Necroptosis is a regulated form of necrosis, which may be critical in the pathogenesis of neurodegenerative diseases. Neuroinflammation, characterized by the activation of glial cells such as microglia, is closely linked with neurodegenerative pathways and constitutes a major mechanism of neural damage and disease progression. Importantly, inhibition of necroptosis results in disease improvement, unveiling an alternative approach for therapeutic intervention. In the present study, we screened a small library of new molecules, potentially inhibitors of necroptosis, using two cellular models of necroptosis. A new oxazolone, Oxa12, reduced tumour necrosis factor a (TNF-a)-induced necroptosis in mouse L929 fibrosarcoma cells. Notably, Oxa12 strongly inhibited zVAD-fmk-induced necroptosis in murine BV2 microglial cells. Moreover, Oxa12 blocked phosphorylation of mixed-lineage kinase domain-like protein (MLKL), and interfered with necrosome complex formation, indicating that Oxa12 targets components upstream of MLKL. In fact, in silico molecular docking studies revealed that Oxa12 is occupying a region similar to the 1aminoisoquinoline type II kinase inhibitor inside the receptor-interacting protein 1 (RIP1) kinase domain. Finally, in microglial cells, Oxa12 attenuated zVAD-fmk- and lipopolysaccharide (LPS)-induced inflammatory processes, as revealed by a marked decrease of TNF-a and/or IL-1 $\beta$ expression. More specifically, Oxa12 negatively targeted c-Jun Nterminal kinase (JNK) and p38 mitogen-activated protein kinase (MAPK) pathways, as well as NF-KB activation. Overall, we identified a strong lead inhibitor of necroptosis that is also effective at reducing inflammation-associated events. Oxa12 is a promising candidate molecule for further development to target disease states dependent on RIP kinase activity.
\end{abstract}

\section{Introduction}

Neurodegenerative diseases are a group of chronic disorders characterized by progressive neuronal dysfunction and loss in specific areas of the nervous system. Neuroinflammation has also emerged as a critical mechanism contributing to neuronal damage and fuelling disease progress.

\footnotetext{
Correspondence: Joana D. Amaral (jamaral@ff.ulisboa.pt) or

Cecília M. P. Rodrigues (cmprodrigues@ff.ulisboa.pt)

${ }^{1}$ Research Institute for Medicines (iMed.ULisboa), Faculty of Pharmacy,

Universidade de Lisboa, Lisboa, Portugal
}

Edited by I. Lavrik
Necrosis has historically been considered an accidental and passive cell death mechanism ${ }^{1,2}$. However, evidence now reveals that a subtype of necrosis, necroptosis, can be molecularly controlled ${ }^{3}$, and viewed as an appealing target for therapeutic intervention. Necroptosis is a caspaseindependent form of cell death that can be activated by death receptors, particularly tumour necrosis factor receptor 1 (TNFR1), as well as Toll-like receptor 3 (TLR3), and TLR4 ${ }^{4,5}$. Downstream signalling involves auto- and trans-phosphorylation of receptor-interacting protein 1 (RIP1) and 3 (RIP3), converging on the assembly of an amyloid-like structure, named necrosome ${ }^{6}$. RIP3 then recruits and phosphorylates pseudokinase mixed 


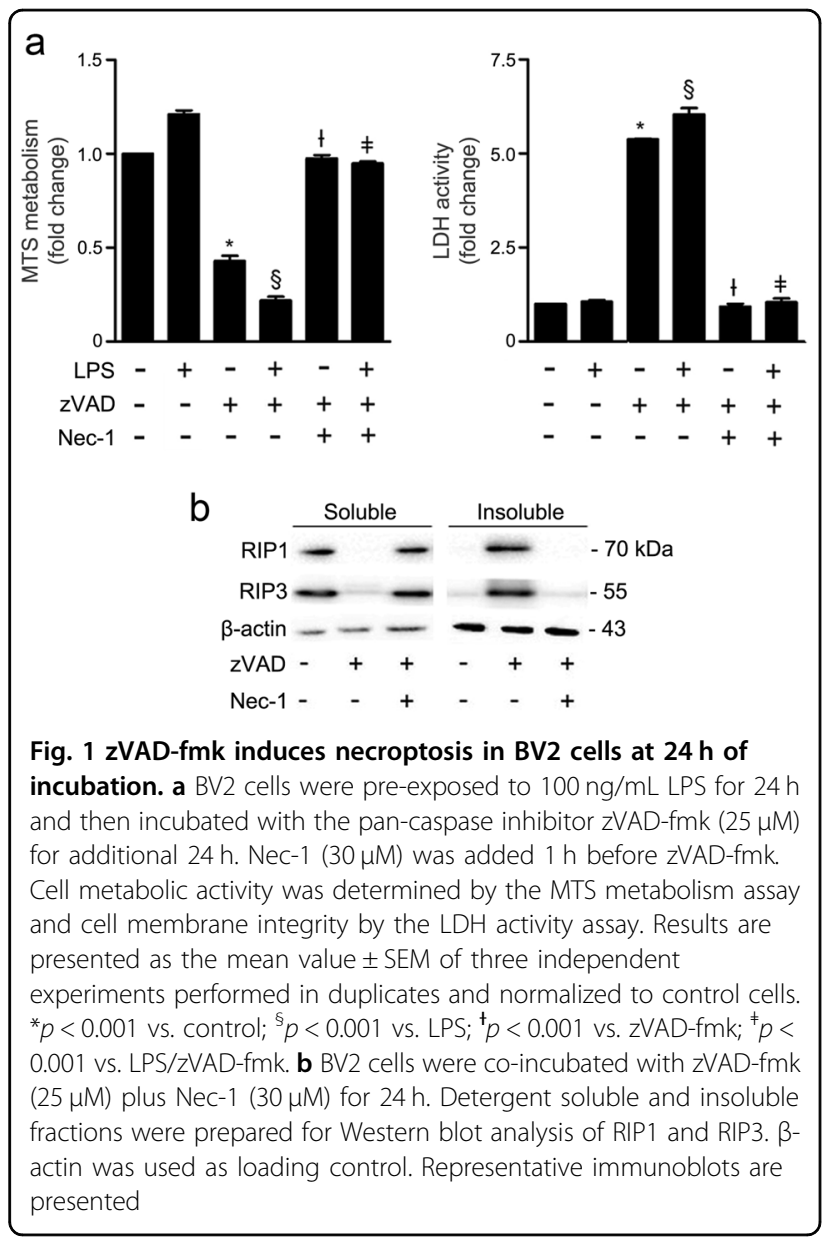

lineage kinase domain-like (MLKL), which in turn triggers membrane rupture, resulting in necroptotic cell death ${ }^{7-9}$.

The role of necroptosis in disease was first investigated in ischemic brain injury ${ }^{10}$. Since then, necroptosis has emerged as a critical event in the pathogenesis of other diseases, namely inflammatory diseases such as pancreatitis $^{11}$, skin inflammation ${ }^{12}$, and liver injury ${ }^{13}$, but also neurodegenerative diseases. Indeed, necroptosis has been reported in Huntington's disease ${ }^{3}$, amyotrophic lateral sclerosis $^{14}$, multiple sclerosis ${ }^{15}$, Alzheimer's disease ${ }^{16}$ and Parkinson's disease ${ }^{17}$, while both genetic and chemical inhibition of necroptosis results in disease improvement.

Pharmacological targeting of necroptosis has been attempted using necrostatin-1 (Nec-1), a strong inhibitor of RIP1 kinase activity ${ }^{10}$. Other molecules targeting components of the necroptotic signalling pathway have been described ${ }^{8,18}$; however, none is available for clinical use. Here, we propose a robust in vitro model to screen for necroptosis inhibitors based on the murine BV2 microglial cell line. Oxa12 was identified as a potent inhibitor of necroptosis in BV2 cells and further confirmed in L929 cells. Moreover, Oxa12 attenuated neuroinflammation, highlighting the potential benefit of necroptosis inhibitors to halt neurodegenerative diseases.

\section{Results}

zVAD-fmk induces necroptosis in BV2 microglia cells

Previous studies have demonstrated that primary microglia undergo RIP1/RIP3-dependent necroptosis after treatment with LPS or other TLR ligands, when caspases are inhibited $^{19,20}$. Other authors showed that the pan- caspase inhibitor zVAD-fmk induces necroptosis in the L929 fibrosarcoma cell line by a mechanism that depends on autocrine production of TNF- $\alpha^{21,22}$. Here, we anticipated a new in vitro model for the study of microglial necroptosis, based on the murine BV2 microglial cell line. Exposure of BV2 cells to LPS for $48 \mathrm{~h}$ did not induce cell death, as detected by MTS metabolism and LDH release (Fig. 1a). However, when cells were exposed to LPS for $24 \mathrm{~h}$ followed by incubation with zVAD-fmk for additional $24 \mathrm{~h}$, cell viability was reduced by $\sim 80 \%$ ( $p<$ $0.001)$ with a concomitant increase in cell death. Importantly, the presence of zVAD-fmk alone was sufficient to induce high levels of cell death $(p<0.001)$. Addition of Nec-1, a RIP1-specific kinase inhibitor, fully reverted cell death to control levels in all conditions tested $(p<0.001)$, thus implicating RIP1-dependent necroptosis as the mechanism of cell death.

Necroptosis activation requires assembly of RIP1 and RIP3 in an insoluble amyloid-like complex called necrosome $^{6}$. Exposure of cells to zVAD-fmk for $24 \mathrm{~h}$, triggered RIP1 and RIP3 sequestration in the insoluble fraction (Fig. 1b), corroborating the viability data, thus confirming functional necrosome assembly and necroptosis activation. Addition of Nec-1 abolished RIP1 and RIP3 sequestration in the insoluble fraction. Taking these results into account, BV2 cells exposed to zVAD-fmk represent a robust in vitro model of microglial necroptosis, which is fully reverted when RIP1 kinase activity is inhibited by Nec-1.

\section{Screening for potential inhibitors of necroptosis}

To identify novel inhibitors of necroptosis, we screened a small library of new compounds for their ability to block zVAD-fmk-induced necroptosis using the BV2 cell line model (Fig. 2a). Among the compounds tested, one potential hit was identified that significantly rescued BV2 cell viability $(p<0.05)$ (Fig. $2 \mathrm{~b})$. As proof-of-concept, we used a well-described model where L929 cells undergo TNF- $\alpha$-induced necroptosis, which in turn is fully reverted by Nec-1 (Fig. 3a). In L929 cells, four compounds were able to revert TNF- $\alpha$-induced cell death $(p<0.05)$ (Fig. 3b). We proceeded with our studies using compound Oxa12 (Fig. 2c) that showed effects similar to Nec-1 in both cell lines. Three different batches of Oxa12 were 


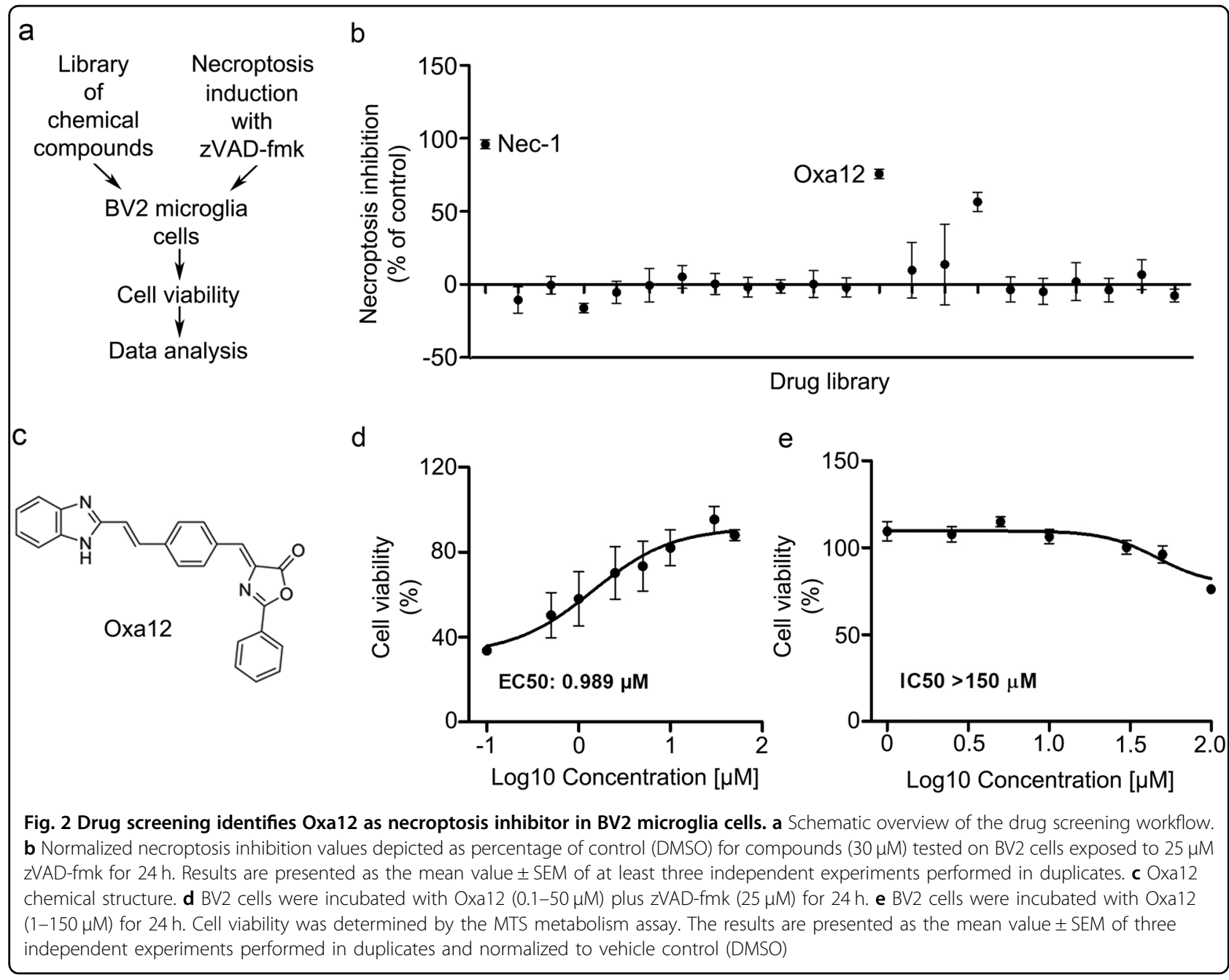

tested, showing the same ability to inhibit necroptosis in both cell models (data not shown).

To further characterize Oxa12 activity and confirm the screening data, we performed dose-response studies and quantitatively assessed its inhibitory potency. The half maximal effective concentration $\left(\mathrm{EC}_{50}\right)$ of Oxa12 for inhibiting necroptosis was determined to be $0.989 \mu \mathrm{M}$ in BV2 cells (Fig. 2d) and $0.398 \mu \mathrm{M}$ in L929 cells (Fig. 3c). Drug toxicity was also assessed by determining the half maximal inhibitory concentration $\left(\mathrm{IC}_{50}\right)$ in $\mathrm{BV} 2$ and in L929 cells. Notably, Oxa12 displayed no cytotoxicity throughout the whole range of concentrations in both cell lines (Figs. $2 \mathrm{e}$ and $3 \mathrm{~d}$ ), with $\mathrm{IC}_{50}$ values greater than $150 \mu \mathrm{M}$, highlighting the wide window of opportunity for inhibiting necroptosis with this compound.

Motivated by these results and to get further insight into the mechanism of action of Oxa12 at the molecular level, we performed in silico molecular docking calculations for Oxa12 inside the RIP1 kinase domain using the 4NEU $\mathrm{X}$-ray structure obtained for this enzyme complexed with 1-aminoisoquinoline type II kinase inhibitor ${ }^{23}$. Our results revealed that without any constrain, Oxa12 is occupying a region similar to the co-crystallized inhibitor, with the phenyl rings from both compounds almost overlapped, suggesting a similar interaction pattern (Fig. 4a). Oxa12, however, is slightly rotated in the binding pocket when compared with the crystallographic ligand, being close to Asp156, Leu157, Met67, and Met95, which may enable important hydrogen bonds and $\pi$ interactions. Oxa12 showed slightly increased interaction distances in comparison to the crystallographic inhibitor (Fig. 4b).

\section{Oxa12 is a potent inhibitor of necroptosis}

To determine the effect of Oxa12 in the necroptotic signalling pathway, we co-incubated BV2 cells with zVAD-fmk and Oxa12 for $24 \mathrm{~h}$ and evaluated necrosome assembly and MLKL phosphorylation in the detergentinsoluble proteome. During necroptosis, MLKL is phosphorylated at Thr357/Ser358 residues (p-MLKL) by RIP3 kinase. Once phosphorylated, MLKL oligomerizes and 


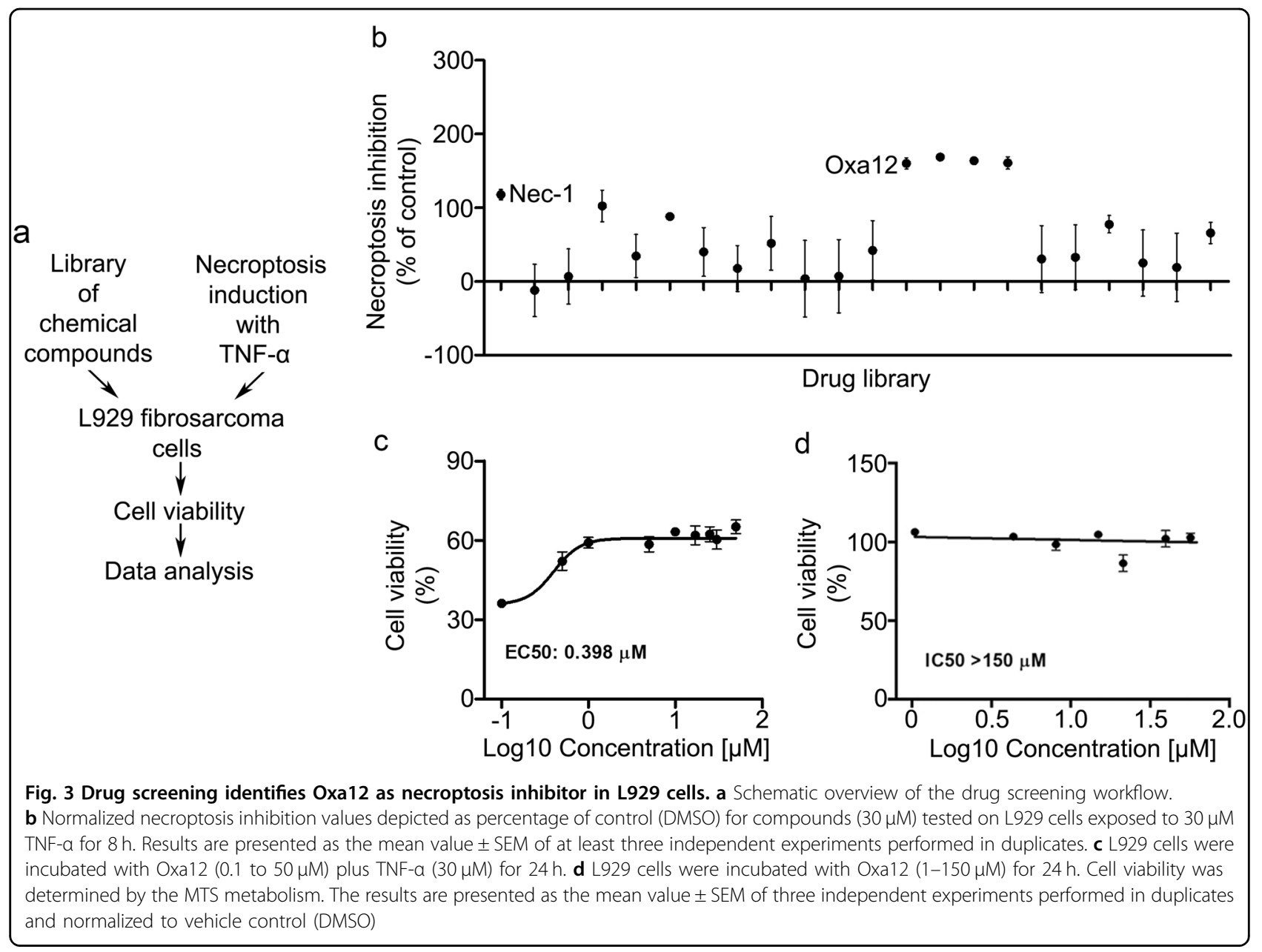

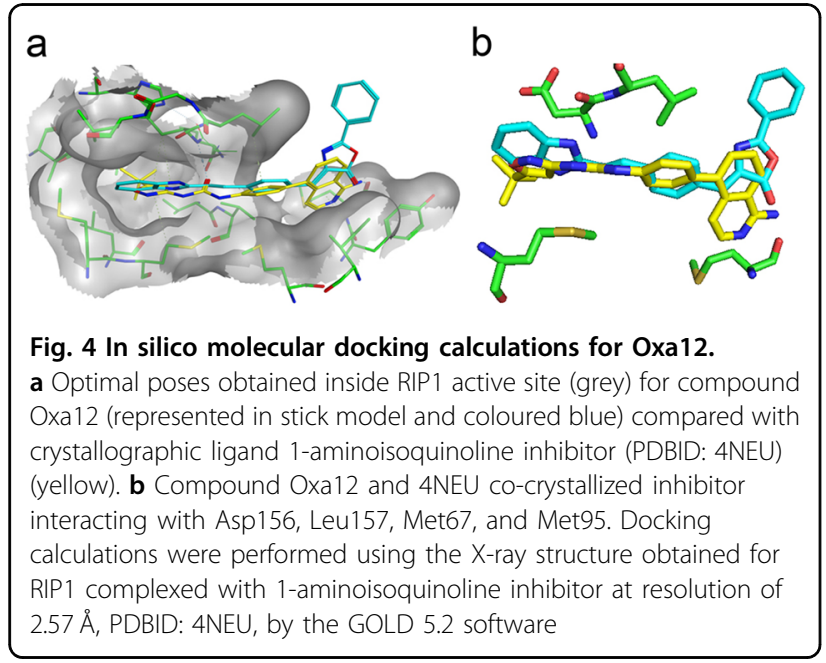

ultimately induces cell membrane disruption, being an excellent marker of necroptosis commitment ${ }^{15}$. Exposure of BV2 cells to zVAD-fmk promoted the sequestration of all key components of the necroptosis machinery, RIP1, RIP3, and $\mathrm{p}-\mathrm{MLKL}$, in the insoluble fraction $(p<0.01)$
(Fig. 5a, b). Nec-1 abrogated both necrosome assembly and MLKL phosphorylation $(p<0.01)$. Importantly, Oxa12 also abolished all necroptosis-associated changes $(p<0.05)$.

Microscopy analysis of cell morphology was consistent with the previous results, showing evident cell death after zVAD-fmk treatment and improvement of this phenotype when Nec-1 or Oxa12 were added to BV2 (Fig. 5c). Of note, neither Nec-1 nor Oxa12 alone affected cell morphology. The effect of Oxa12 was further confirmed in L929 cells, in which Oxa12 prevented TNF- $\alpha$-induced increase of $\mathrm{p}$-MLKL $(p<0.05)$ and preserved cell morphology (Suppl. Figure 1a and b). Taken together, these results implicate Oxa12 as a strong inhibitor of necroptosis.

\section{Oxa12 reduces TNF- $a$ gene expression and secretion}

Necroptosis is a proinflammatory type of cell death that culminates in the release of intracellular components to the extracellular space ${ }^{24}$. Moreover, zVADfmk-induced necroptosis in L929 cells is dependent on the production and autocrine secretion of TNF- $\alpha^{22}$. To 


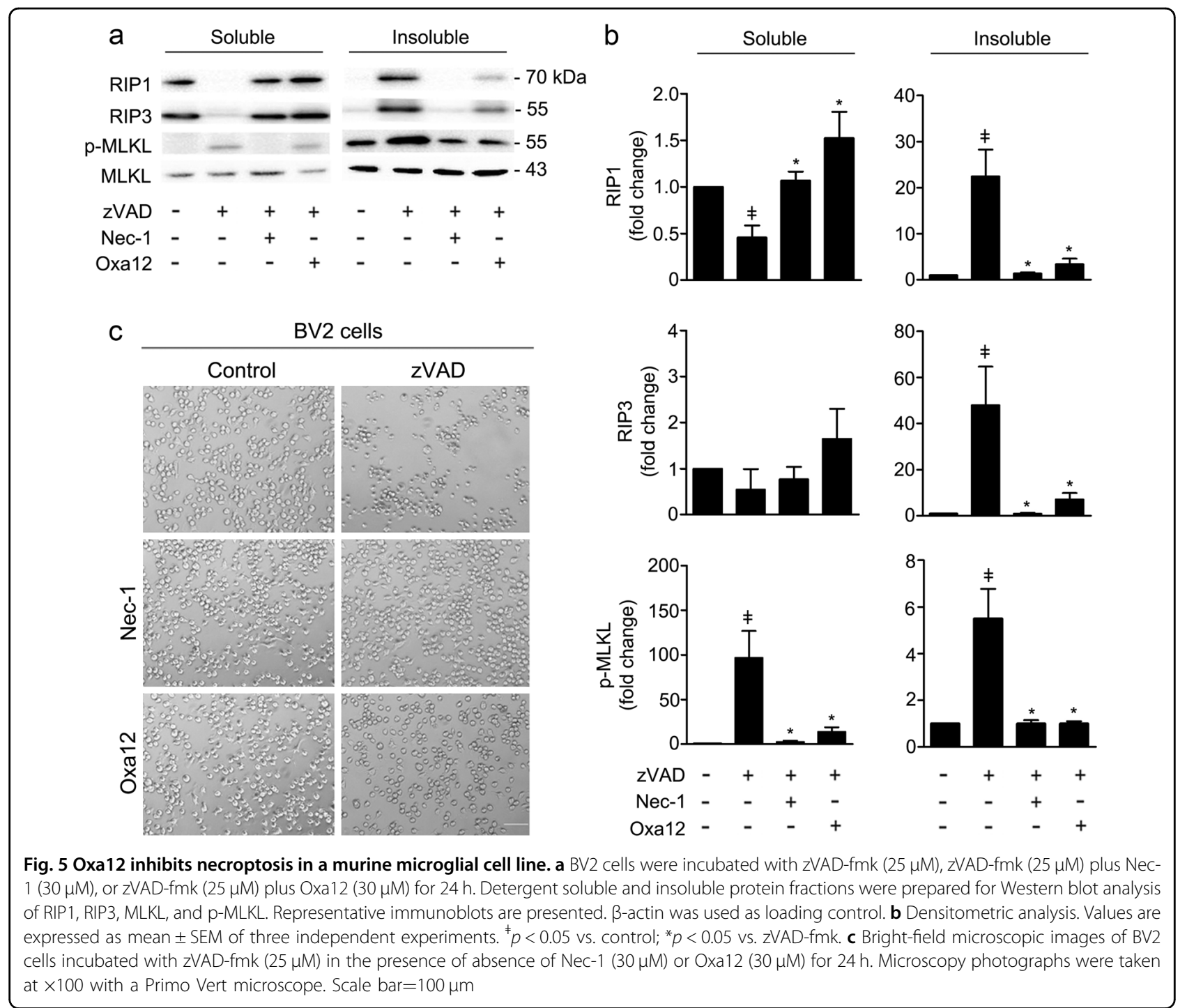

determine whether Oxa12-mediated inhibition of necroptosis may also contribute to decrease necroptosis-associated inflammation, we analysed mRNA levels of proinflammatory genes, including cyclooxygenase 2 (COX2), interleukin-6 (IL-6), nucleotide-binding oligomerization domain-like receptor (NLR) pyrin domain containing 3 (NLRP3), and $T N F-\alpha$, as well as TNF- $\alpha$ protein secretion to the culture medium. COX2 and NLRP3 did not show any significant variation, with either zVAD-fmk alone or in combination with Nec-1/Oxa12, while $I L-6$ was barely detectable in all conditions tested (data not shown). In contrast, exposure of BV2 cells to zVAD-fmk for $24 \mathrm{~h}$ resulted in a significant increase of TNF- $\alpha$ gene expression $(p<0.001)$ and protein secretion levels $(p<$ 0.05) (Fig. 6a). Importantly, at the mRNA level, this increase was significantly reduced upon Nec-1 and Oxa12 incubation $(p<0.05)$. Similarly, Nec-1 completely abolished zVAD-fmk-induced TNF- $\alpha$ secretion, while Oxa12 diminished TNF- $\alpha$ levels in the culture medium by about $70 \%(p<0.05)$. These results suggest that, similarly to what was described for L929 cells, the autocrine secretion of TNF- $\alpha$ is a key step in zVAD-fmk-induced necroptosis in BV2 microglia cells, and Oxa12 appears to counteract this proinflammatory condition.

To determine if Oxa12 could play a role in protecting BV2 microglia cells from an inflammatory stimulus, per se, we investigated $T N F-\alpha$ and $I L-1 \beta$ gene expression after stimulation of BV2 cells with LPS. As expected, exposure of BV2 cells to LPS significantly increased TNF$\alpha$ and $I L-1 \beta$ gene expression $(p<0.001)$, an effect exacerbated by LPS/zVAD-fmk co-incubation $(p<0.001)$ (Fig. 6b). Moreover, Nec-1 robustly reduced TNF- $\alpha$ and $I L-1 \beta$ mRNA levels $(p<0.001)$, which is in accordance with previous studies ${ }^{25-27}$. Notably, Oxa12 partially reverted LPS- and LPS/zVAD-fmk-induced TNF- $\alpha$ and $I L-1 \beta$ gene expression $(p<0.001)$, thus highlighting the anti-inflammatory potential of this compound. 

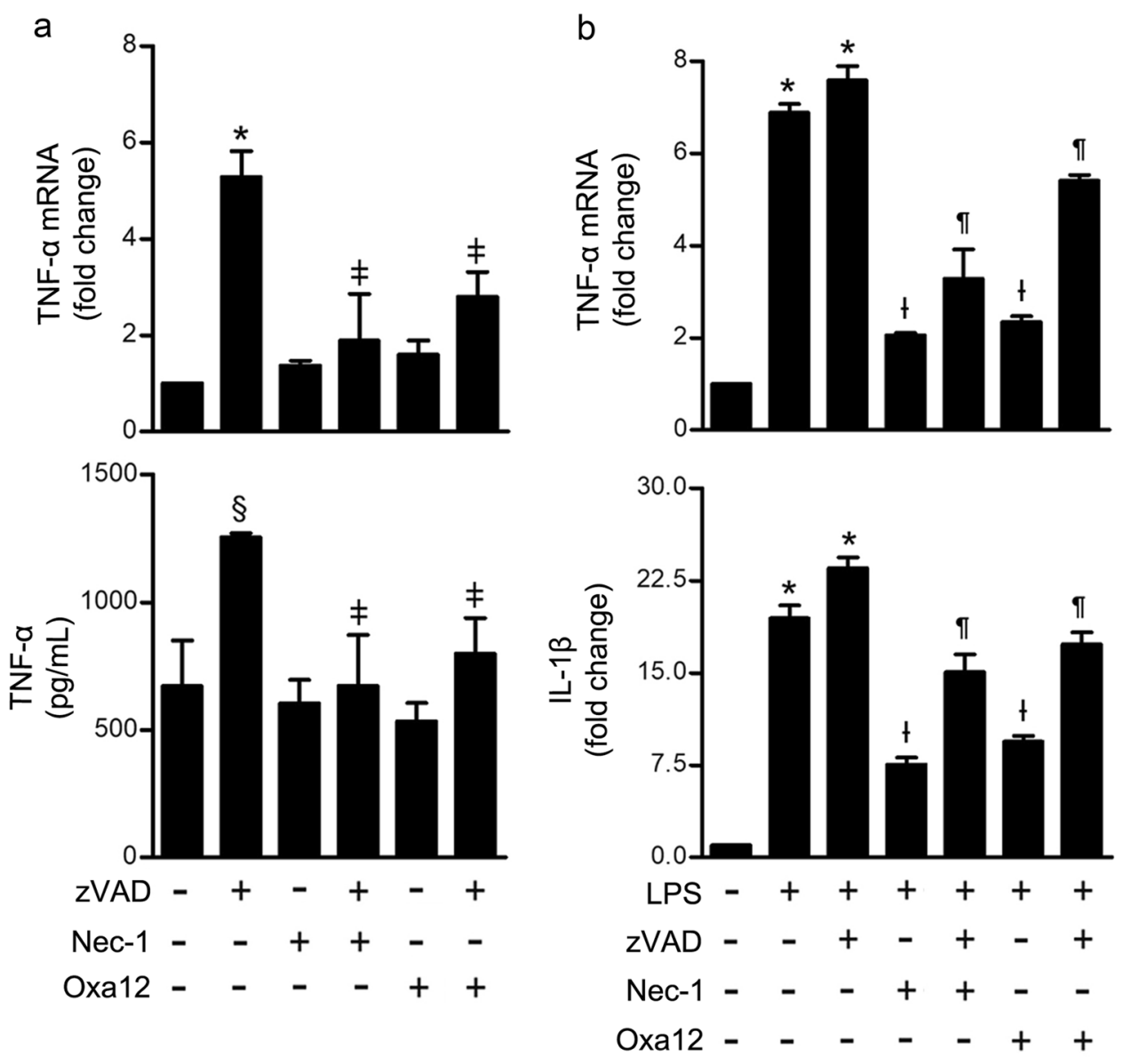

Fig. 6 Oxa12 decreases TNF-a gene expression and protein secretion levels. a BV2 cells were incubated with zVAD-fmk ( $25 \mu M)$ in the presence or absence of Nec-1 $(30 \mu \mathrm{M})$ or Oxa12 $(30 \mu \mathrm{M})$ for $24 \mathrm{~h}$. TNF-a mRNA levels were measured by qRT-PCR and secreted TNF-a by ELISA. Results are expressed as mean \pm SEM from three independent experiments. ${ }^{*} p<0.001$ vs. control; ${ }^{*} p<0.001$ Vs. ZVAD-fmk. b BV2 cells were incubated with $100 \mathrm{ng} / \mathrm{mL}$ LPS, LPS plus zVAD-fmk $(25 \mu \mathrm{M})$ in the presence or absence of Nec-1 $(30 \mu \mathrm{M})$ or Oxa12 $(30 \mu \mathrm{M})$ for $24 \mathrm{~h}$. TNF-a and IL-1 3 mRNA levels were measured and results are expressed as mean \pm SEM from three independent experiments. ${ }^{*} p<0.001$ vs. control; ${ }^{+} p<0.001$ vs. LPS; ${ }^{9} p<0.001$ vs. LPS/ zVAD-fmk

\section{Oxa12 inhibits zVAD-fmk-induced JNK, p38 MAPK and NF-KB activation}

To further dissect which inflammatory pathways Oxa12 specifically targets, we evaluated JNK (Thr183/ Tyr185) and p38 (Thr180/Tyr182) phosphorylation, two classic MAPK inflammatory signalling pathways. We also evaluated phosphorylation of protein kinase $\mathrm{B}$, also known as Akt (Ser473). Indeed, others have shown that JNK and Akt, when activated, have important roles in necroptosis, being involved in the production and autocrine secretion of TNF- $\alpha^{21}$. Incubation of BV2 cells with zVAD-fmk for $24 \mathrm{~h}$ induced a significant increase in JNK and p38 phosphorylation, thus suggesting activation of these two signalling pathways (Fig. 7a, b). In contrast, Nec-1 completely abolished JNK and p38 phosphorylation, while treatment with Oxa12 markedly reduced their activation. No significant changes were observed for Akt activation under these experimental conditions (Fig. 7c).
NF- $\mathrm{kB}$ has long been considered a pivotal mediator of inflammatory responses ${ }^{27}$, largely based on its activation by proinflammatory cytokines such as TNF- $\alpha$. We investigated whether NF- $\mathrm{kB}$ signalling was activated in BV2 cells after exposure to zVAD-fmk. No significant differences were observed in NF- $\mathrm{kB}$ steady-state levels upon exposure of BV2 cells to zVAD-fmk (Fig. 8a). However, IкB was markedly decreased $(p<0.01)$ with a concomitant increase of the $\mathrm{NF}-\kappa \mathrm{B} / \mathrm{I}_{\kappa} \mathrm{B}$ ratio $(p<0.01)$, suggesting that $z V A D-f m k$ treatment induced NF- $\mathrm{B}$ activation (Fig. 8a). Importantly, NF- $\mathrm{B}$ activation was further confirmed by immunofluorescence. BV2 cells treated with $\mathrm{zVAD}$-fmk for $5 \mathrm{~h}$ showed a marked increase of NF-kB p65 subunit in the nucleus (Fig. 8b). In contrast, both Nec-1 and Oxa12 strongly suppressed zVAD-fmkdriven NF- $\mathrm{kB}$ activation $(p<0.01)$. 


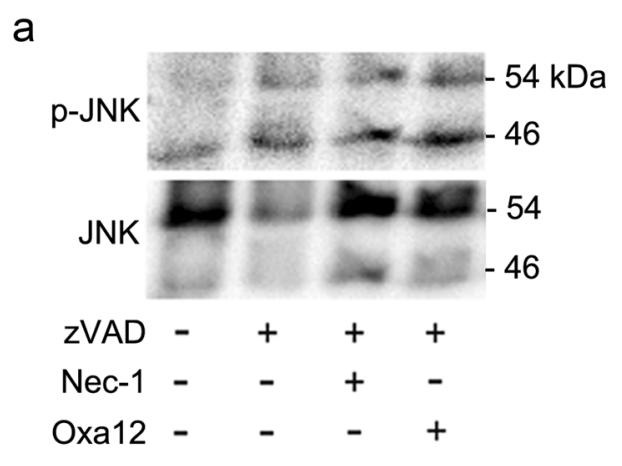

b
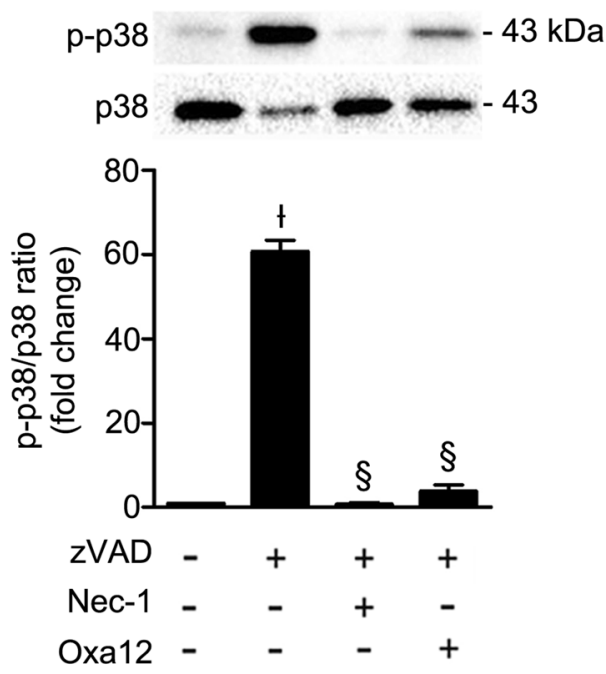

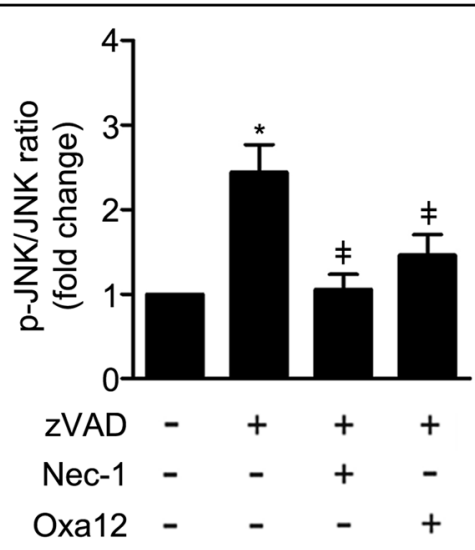

C
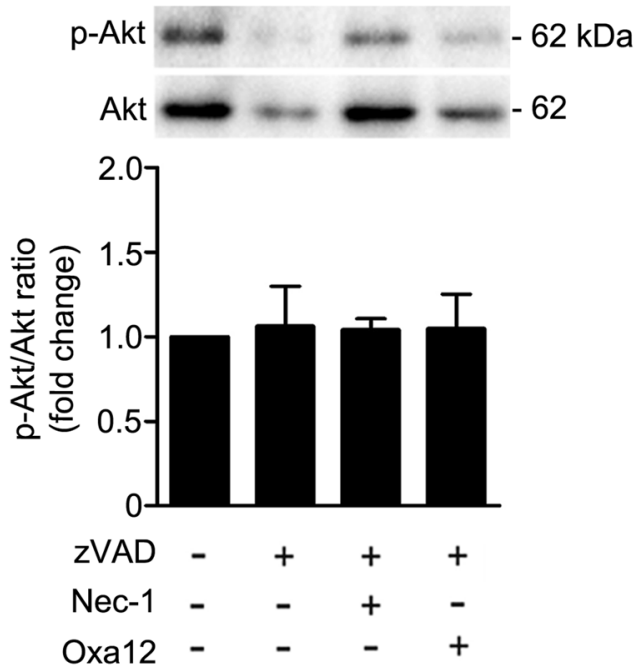

Fig. 7 Oxa12 decreases zVAD-fmk-induced JNK and p38 MAPK activation in BV2 cells. BV2 cells were treated with zVAD-fmk (25 $\mu$ M) in the presence or absence of Nec-1 $(30 \mu \mathrm{M})$ or Oxa12 $(30 \mu \mathrm{M})$ for $24 \mathrm{~h}$. Representative immunoblots are presented, together with the respective densitometric analysis of the p-JNKJJNK, p-p38/p38 and p-Akt/Akt ratios. a p-JNK (Thr183/Tyr185) and total JNK. b p-p38 (Thr180/Tyr182) and total p38. c p-Akt (Ser473) and total Akt. Results are expressed as mean \pm SEM of three independent experiments. ${ }^{*} p<0.001$ vs. control; ${ }^{\ddagger} p<0.05$ vs. zVADfmk; ${ }^{\dagger} p<0.01$ vs. control; ${ }^{\S} p<0.001$ vs. zVAD-fmk

\section{Discussion}

Neurological disorders ranked as the leading cause group of disability, and the second-leading cause of mortality worldwide ${ }^{28}$. Globally, the burden of neurodegenerative diseases is expected to increase over the next years, mostly because of the expanding population and ageing. Currently, the treatments available are ineffective. Therefore, interventions that slow or stop neurodegeneration are an urgent, unmet need. Although apoptosis is frequently implicated in neurodegeneration, necroptosis has been recently described as a prominent player in neurodegenerative disease pathobiology ${ }^{3}$. In fact, the role of necroptosis has been studied in the pathogenesis of a broad spectrum of diseases, including neurodegenerative diseases, where inhibition of necroptosis is considered a beneficial event ${ }^{14-17}$. Neuroinflammation is also a pathological hallmark of neurodegenerative diseases, where microglia have a fundamental role in regulating innate and adaptive immune responses ${ }^{29,30}$. Recently it was shown that in certain pathological conditions, such as multiple sclerosis, microglia present defective caspase- 8 activation, which may promote inflammation through activation of necroptosis, thus contributing to disease progression ${ }^{15}$. Others have also shown that necroptosis in retina microglia triggers neuroinflammation and exacerbates retinal neural damage and degeneration in mice ${ }^{25}$. In these cases, targeting the necroptotic machinery has been proven to be useful to attenuate microglia-mediated neuroinflammation and ameliorate neural injury.

Here, we used the murine BV2 microglia cell line as a new and robust cellular model to screen for potential small molecule modulators of microglial necroptosis. Our results showed that BV2 cells undergo necroptosis after $24 \mathrm{~h}$ incubation with the pan- caspase inhibitor, zVAD- 

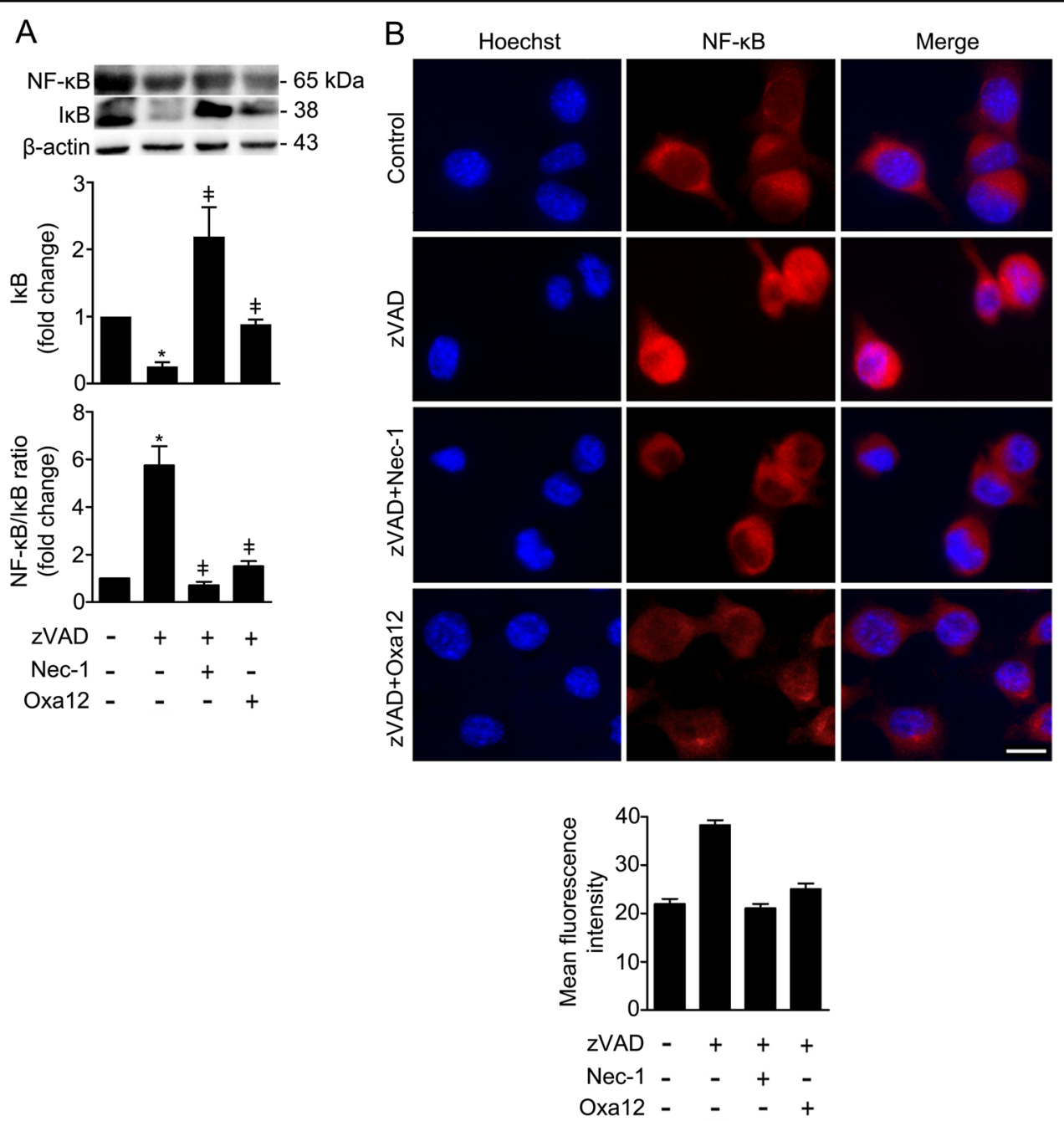

Fig. 8 Oxa12 reduces NF-KB/lKB ratio and NF-KB p65 nuclear translocation when compared to zVAD-fmk-treated cells. a BV2 cells were incubated with zVAD-fmk $(25 \mu \mathrm{M})$ in the presence or absence of Nec-1 $(30 \mu \mathrm{M})$ or Oxa12 (30 $\mu \mathrm{M})$ for $24 \mathrm{~h}$. Representative immunoblots of total NF-KB are presented together with the respective densitometric analysis of NF- KB/lkB ratio. $\beta$-actin was used as loading control. Results are expressed as mean \pm SEM from three independent experiments. ${ }^{*} p<0.05$ vs. control; ${ }^{\ddagger} p<0.05$ vs. ZVAD-fmk. $\mathbf{b}$ Representative images of immunofluorescence staining showing NF-kB p65 (red) nuclear translocation in BV2 cells treated with zVAD-fmk ( $25 \mu \mathrm{M})$ in the presence or absence of Nec-1 (30 $\mu \mathrm{M})$ or Oxa12 $(30 \mu \mathrm{M})$ for $5 \mathrm{~h}$, and quantification of mean fluorescence intensity. Cell nuclei were detected by Hoechst (blue). Scale bar=1 $\mu \mathrm{m}$

fmk, which is in agreement with previous studies reporting that zVAD-fmk induces necroptosis in L929 cells $^{21,22}$. Nec-1, a RIP1 kinase inhibitor here used as positive control of necroptosis inhibition, fully reverted cell death to control levels, thus implicating RIP1dependent necroptosis as the death mechanism. Interestingly, pre-incubation with LPS, a well-known TLR4 agonist, accelerated the death mechanism, thus linking necroptosis to this inflammatory context. Indeed, we observed a further decrease of $\sim 30 \%$ in MTS metabolism when cells were pre-incubated with LPS for $24 \mathrm{~h}$ and, then, incubated with zVAD-fmk for additional $24 \mathrm{~h}$, while no differences were observed in LDH activity. These results suggest that cell membrane permeabilization and leakage of intracellular components, such as LDH, may be an initial step in the necroptotic cascade, while mitochondria dysfunction appears to contribute indirectly to late-stage necroptosis ${ }^{9,31}$. In addition, we observed that zVAD-fmk alone induced necrosome assembly after $24 \mathrm{~h}$. It is known that zVAD-fmk triggers the production of TNF- $\alpha$ at the transcriptional level, and subsequently the autocrine secretion of this cytokine, which in turn may activate TNFR to induce necroptosis ${ }^{22}$. Reversion of necrosome formation induced by Nec-1 further confirmed the importance of this molecular platform as the cell death inducer in this model. Overall, BV2 cells exposed to zVAD-fmk represent a robust in vitro model of microglial necroptosis, along with full reversion of all 
necroptotic processes when RIP1 kinase activity is inhibited by Nec-1.

Since the discovery of Nec-1 as the first inhibitor of necroptosis ${ }^{10}$, other inhibitors have been described, including RIP1, RIP3 and MLKL inhibitors. Nonetheless, all compounds identified so far show several limitations. Nec-1 itself is highly effective in inhibiting necroptosis; however, it has inadequate pharmacokinetic properties including very short in vivo half-life of $\sim 1 \mathrm{~h}$, reduced solubility ${ }^{32}$, and presents off-target activity against indoleamine-pyrrole 2,3-dioxygenase (IDO), a modulator of the innate and adaptive immune system ${ }^{33,34}$, serine/threonine-protein kinase 1 (PAK1) and cAMPdependent protein kinase catalytic subunit $\alpha$ (PKAc $\alpha$ ). Later, Nec-1 optimizations led to the identification of Nec-1s (Nec-1 stable), also known as 7-Cl-O-Nec-1, which is a selective RIP1 kinase inhibitor with low toxicity. However, this molecule has also poor pharmacokinetic properties ${ }^{33,34}$. Regarding RIP3 inhibitors, all compounds described so far also induce apoptosis ${ }^{18}$. Necrosulfonamide (NSA), a well-known MLKL inhibitor, inhibits necroptosis by blocking human MLKL phosphorylation, but not the rodent homolog, thus invalidating pharmacological, pharmacokinetic and toxicity preclinical testing ${ }^{8}$. In sum, although tool compounds blocking necroptosis have previously been developed, no necroptosis inhibitors are in clinical use to date. Therefore, the discovery of new specific and potent pharmacologic inhibitors of necroptosis is relevant and of utmost importance.

In this study, we screened a library of new compounds that potentially modulate necroptosis. We identified one hit, Oxa12, that inhibits necroptotic cell death in BV2 cells $\left(\mathrm{EC}_{50}=0.989 \mu \mathrm{M}\right)$ and L929 cells $\left(\mathrm{EC}_{50}=0.459 \mu \mathrm{M}\right)$ without cytotoxicity associated. Further, Oxa12 inhibited necroptosis-associated events in murine BV2 cells, including necrosome assembly and MLKL S358 phosphorylation, two key markers of necroptosis commitment. Importantly, the docking pose of Oxa12 inside RIP1 kinase active site is similar to that of the co-crystallized 1aminoisoquinoline RIP1-specific inhibitor, thus highlighting the potential of Oxa12 as a RIP1 inhibitor.

To further characterize the mechanism of action of Oxa12 and because necroptosis is an inflammatory type of cell death, we hypothesized that necroptosis inhibition by Oxa12 could also result in decreased inflammation. Our results showed that BV2 cells exposed to zVAD-fmk presented increased levels of TNF- $\alpha$ gene expression and cytokine secretion. These findings were in accordance with previous studies reporting the production and autocrine secretion of TNF- $\alpha$ as a crucial factor in zVADfmk-induced necroptosis ${ }^{22,35}$. No differences were detected in COX2 and NLRP3 transcription levels, which might be explained by the involvement of these two proteins in later stages of the inflammatory cascade, being extensively regulated by other proteins and signalling pathways ${ }^{36,37}$. Similarly to what happens with Nec-1, treatment of BV2 cells with Oxa12 reduced TNF- $\alpha$ gene expression and cytokine secretion levels, suggesting that RIP1 kinase activity is required for TNF- $\alpha$ production, as previously reported $^{21}$.

After confirming the involvement of necroptosisassociated inflammation in our cellular model and its concomitant reduction by Oxa12, we further investigated if Oxa12 could protect BV2 microglial cells from a classic inflammatory stimulus, independent of necroptosis activation. Therefore, we used LPS, a specific ligand of TLR4 that activates downstream pro-inflammatory signalling cascades without eliciting cell death. As expected, treatment of BV2 cells with LPS for $24 \mathrm{~h}$ induced TNF- $\alpha$ and $I L-1 \beta$ gene expression. Curiously, Nec-1 counteracted the effect of LPS implicating RIP1 in the production of proinflammatory cytokines, unrelated to necroptosis. In fact, this was not the first time that an anti-inflammatory role was reported for Nec-1, independently of its activity as necroptosis inhibitor ${ }^{38}$. Similarly, Oxa12 strongly inhibited LPS-induced TNF- $\alpha$ and $I L-1 \beta$ mRNA levels, thus revealing the potential of this molecule not only as an inhibitor of necroptosis, but also as an agent with ability to resolve established inflammation. Exposure of LPSstimulated BV2 cells to zVAD-fmk further potentiated the transcription of proinflammatory $T N F-\alpha$ and $I L-1 \beta$, suggesting that caspase blockade sensitizes cells to LPS challenge. Nonetheless, both Nec-1 and Oxa12 were still capable of reducing LPS/zVAD-fmk-induced proinflammatory mediators.

To better understand which inflammatory pathways Oxa12 specifically targeted, we evaluated the activation of two MAPK signalling pathways, JNK and p38, as well as the activation of Akt. Importantly, activated MAPK signalling pathways are described in the pathogenesis of neurodegenerative diseases, including Alzheimer's disease and Parkinson's disease as contributors of inflammation and neuronal death ${ }^{39-41}$. Deregulation of Akt pathway is also reported in brains from Alzheimer's and Parkinson's disease patients ${ }^{42}$. Recent studies have reported that JNK activation plays an important role during zVAD-fmkinduced necroptosis in L929 cells downstream to RIP1 kinase, promoting TNF- $\alpha$ gene expression ${ }^{21,22}$. Increased TNF- $\alpha$ transcription may translate into elevated levels of this cytokine, which could induce necroptosis through TNFR activation ${ }^{22}$. Our results are in line with these studies, since exposure of BV2 cells to zVAD-fmk induced high levels of JNK activation, which may be related with the increase observed in TNF- $\alpha$ gene expression and cytokine secretion levels. By contrast, Nec-1 and Oxa12 abolished both JNK activation and TNF- $\alpha$ gene expression and cytokine secretion levels, thus confirming the 
involvement of this signalling pathway in zVAD-fmkinduced necroptosis. Regarding p38, while some authors reported that this signalling pathway is not activated during necroptosis in L929 cells ${ }^{43}$, others show that pharmacological inhibition of TNF- $\alpha$-induced necroptosis in $\mathrm{L} 929$ cells resulted in p38 activation ${ }^{44}$. Here, we show that treatment of BV2 cells with zVAD-fmk induced a marked increase in p38 phosphorylation, which is fully reverted by Nec-1 and Oxa12, suggesting activation of this signaling pathway during zVAD-fmk-mediated necroptosis in BV2 microglial cells. It is well known that JNK and p38 MAPK pathways are activated by several inflammatory mediators in different cell lines, being involved in stress responses and inflammation ${ }^{45}$, being possible that the intracellular components released by necroptotic cells may induce JNK and p38 MAPK activation.

The role of Akt in necroptosis has also been demonstrated. Akt is linked to necroptosis in L929 cells, where it plays a key role in mediating TNF- $\alpha$ synthesis ${ }^{46}$. Inhibition of Akt protected L929 cells from TNF- $\alpha$-induced necroptosis and triggers autophagy instead ${ }^{46,47}$. In contrast, others showed that zVAD-fmk alone is capable of inducing Akt activation, with this activation being dependent of Thr308 phosphorylation, with no alterations observed in Akt Ser473 phosphorylation ${ }^{48}$. In the present study, we evaluated Akt Ser473 phosphorylation as a marker of Akt activation, which may explain the absence of significant differences between the conditions tested.

In the nervous system, evidence supports a dual role of $\mathrm{NF}-\kappa \mathrm{B}$ in neurodegenerative diseases. In general, it appears that activation of NF- $\mathrm{KB}$ in neurons protects against degeneration, whereas activation in glial cells mediates pathological inflammatory processes ${ }^{49}$. Taking this into account, we were not surprised by the activation of NF-kB in BV2 cells treated with zVAD-fmk. In contrast, Nec-1 and Oxa12 strongly abrogated this activation, which highlights their potential at reducing inflammationassociated events. Altogether, our findings suggest that zVAD-fmk induces the expression of inflammatory target genes at early time-points, thus promoting the downstream activation of important inflammatory signalling pathways. Further, longer incubation times will activate necroptosis, which has also a prominent role on inflammation ${ }^{50}$.

Overall, we established a robust in vitro model of microglia necroptosis, based on the murine BV2 microglial cell line and identified a strong lead inhibitor of this type of regulated cell death. Oxa12 is efficient at decreasing necroptosis-driven inflammation, as well as activation of important signalling pathways including JNK, p38 MAPK and NF-кB. Thus, Oxa12 can now be considered a promising candidate molecule for targeting pathologies-dependent on RIP1-kinase activity.

\section{Materials and methods}

\section{Cell culture and reagents}

BV2 murine microglia cells (kindly provided by Elsa Rodrigues, University of Lisbon) were cultured in RPMI 1640 medium $\left(\mathrm{GIBCO}^{\circledR}\right.$ Life Technologies, Inc. Grand Island, USA), supplemented with $10 \%$ heat inactivated fetal bovine serum (FBS), $1 \%$ antibiotic/antimycotic solution and $1 \%$ GlutaMAX $^{\mathrm{TM}}$ (GIBCO). Throughout experiments, the culture media was replaced by RPMI supplemented with $1 \%$ antibiotic/antimycotic solution, $1 \%$ insulin-transferrin-selenium (RPMI/ITS) and $1 \mathrm{mg} / \mathrm{mL}$ bovine serum albumin (BSA; GIBCO). The L929 murine fibrosarcoma cell line (kindly provided by Junying Yuan, Harvard Medical School) was cultured in DMEM (GIBCO) supplemented with $10 \%$ FBS and 1\% Gluta$\mathrm{MAX}^{\mathrm{TM}}$. Cells were maintained at $37^{\circ} \mathrm{C}$ in a humidified atmosphere of $5 \% \mathrm{CO}_{2}$. Other chemicals used were as follows: LPS from Escherichia coli 055:B5 (\#437625; Calbiochem, San Diego, CA, USA), Nec-1 (Sigma-Aldrich, St. Louis, MO, USA), dimethyl sulfoxide (DMSO; SigmaAldrich), Z-Val-Ala-Asp-fluoromethylketone (zVADfmk) pan- caspase inhibitor (Enzo Life Sciences, Farmingdale, NY, USA), and recombinant murine TNF- $\alpha$ (PeproTech EC Ltd., London, UK). A small in-house library of potential inhibitors of necroptosis was tested, including Oxa 12 ((Z)-4-(4-((E)-2-(1H-benzo[d]imidazol2-yl)vinyl) benzylidene)-2-phenyloxazol-5(4H)-one) that was synthetized accordingly to a reported method ${ }^{51,52}$.

\section{Viability assay}

BV2 cells were plated in 96-well plates at $5 \times 10^{3}$ cells/ well. After $24 \mathrm{~h}$ of cell plating, media was replaced by fresh RPMI/ITS containing $100 \mathrm{ng} / \mathrm{mL}$ LPS, or no addition, and cells were incubated for additional $24 \mathrm{~h}$. Then, BV2 cells were exposed to $25 \mu \mathrm{M}$ zVAD-fmk for additional $24 \mathrm{~h}$. Nec-1 $(30 \mu \mathrm{M})$ was added $1 \mathrm{~h}$ before zVADfmk. Cellular metabolic activity was measured using the CellTiter $96^{\circledR}$ Aqueous Non-Radioactive Cell Proliferation (MTS) Assay (Promega, Madison, WI, USA). Changes in absorbance were measured at $490 \mathrm{~nm}$ using $\mathrm{GloMax}^{\circledR}$ Multi Detection System (Sunnyvale, CA, USA).

\section{General cell death assays}

Cell membrane integrity was evaluated using the lactate dehydrogenase (LDH) Cytotoxicity Kit ${ }^{\text {PLUS }}$ (Roche Diagnostics $\mathrm{GmbH}$, Mannheim, Germany). Briefly, $50 \mu \mathrm{L}$ of cell supernatants were incubated with $50 \mu \mathrm{L}$ of assay substrate for 10-30 min, at room temperature, protected from light. Absorbance readings were measured at $490 \mathrm{~nm}$, with $620 \mathrm{~nm}$ reference wavelengths using a BioRad Model 680 microplate reader. Further, cell death was also determined using the ToxiLight ${ }^{\mathrm{TM}}$ BioAssay Kit (Lonza Walkersville Inc., Walkersville, MD, USA), according to the manufacturer's instructions. The release 
of adenylate kinase enzyme from damaged cells was determined using $10 \mu \mathrm{L}$ each of cell supernatants and bioluminescent cytolysis assay in the microplate reader.

\section{Drug screening}

Drug screening was performed using BV2 and L929 cell lines. BV2 cells were seeded in 96 -well plates at $7 \times 10^{3}$ cells/well; necroptosis was induced using $25 \mu \mathrm{M}$ zVADfmk and compounds were incubated at a final concentration of $30 \mu \mathrm{M}$. Cell viability and death were assessed $24 \mathrm{~h}$ later by MTS and LDH assays. For the L929 cell line, cells were seeded in 384-well plates at $1 \times 10^{3}$ cells/well, necroptosis was induced using $30 \mu \mathrm{M}$ TNF- $\alpha$, and compounds were incubated at a final concentration of $30 \mu \mathrm{M}$. Cell death was assessed $8 \mathrm{~h}$ later using the ToxiLight ${ }^{\mathrm{tu}}$ BioAssay Kit. All measurements were performed in duplicate. A percentage of control was calculated to normalise for variability across different plates. Halfmaximum effective concentration $\left(E_{50}\right)$ at inhibiting necroptosis and half maximal inhibitory concentration $\left(\mathrm{IC}_{50}\right)$ were calculated for the selected hits in both cell lines, using the GraphPad Prism Software version 5.00 (GraphPad Software, Inc., San Diego, CA, USA) with the $\log$ (inhibitor) vs. response (variable slope) function.

\section{Docking studies}

Non-covalent molecular docking calculations were used to understand compound activity against RIP1. 3D structure coordinates of RIP1 were obtained from five different crystal structures at the Protein Data Bank (PDB), 4ITI, 4ITH, 4ITJ, and 4NEU, with a resolution in the range $1.80-2.89 \AA$. Co-crystallized inhibitors and all crystallographic waters were removed. Hydrogen atoms were then added and the protonation states were correctly assigned using the Protonate-3D tool within the Molecular Operating Environment (MOE) 2016.08 software package. All the compounds tested were built and energy minimized using Amber forcefield implemented in MOE 2016.08 software.

Molecular docking studies were then performed using the GoldScore scoring function from GOLD 5.2 software package and each ligand was subjected to 1000 docking runs. For all five structures, the docking protocol was validated using crystallographic ligands; poses were reproducible with RMSD's lower than $1 \AA$ A. In addition, an extra validation of the receptor structure was performed with 10 established RIP1 inhibitors, including Nec-1 and derivatives, GSK962, GSK963, and ponatinib. Significant differences were observed between final poses and scores obtained using 4ITI, 4ITH, 4ITJ, and 4NEU. The 4NEU structure was able to reproduce the experimental activities, while all other structures showed severe penalties in scores due to a very tight active centre. Results presented here were obtained with the 4NEU prepared structure.

\section{Total and soluble/insoluble protein extraction}

For total protein extraction, BV2 cells were plated in $60 \mathrm{~mm}$ culture dishes at $4 \times 10^{5}$ cells/dish, and L929 cells were plated in 6 -well plates at $2.5 \times 10^{5}$ cells/well. Floating and adherent cells were collected directly in nonyl phenoxypolyethoxylethanol (NP-40) lysis buffer (1\% NP-40, $20 \mathrm{mM}$ Tris- $\mathrm{HCl} \mathrm{pH}$ 7.4, $150 \mathrm{mM} \mathrm{NaCl}, 5 \mathrm{mM}$ EDTA, $10 \%$ glycerol, $1 \mathrm{mM}$ dithiothreitol, and $1 \times$ Halt Protease and Phosphatase Inhibitor Cocktail EDTA-free (Pierce, Thermo Fisher Scientific, Rockford, IL, USA)), followed by sonication and centrifugation at $3200 \times g$ during $10 \mathrm{~min}$ at $4{ }^{\circ} \mathrm{C}$. Total protein extracts were recovered and stored at $-80^{\circ} \mathrm{C}$. Protein concentration was determined by the colorimetric Bradford method (Bio-Rad). BSA (Sigma-Aldrich) was used as standard, and absorbance measurements were performed at $595 \mathrm{~nm}$ using the microplate reader (Bio-Rad). To isolate the soluble and detergent-insoluble proteome of BV2 cells, floating and adherent cells were collected in phosphate-buffered saline (PBS)/EDTA, centrifuged at $600 \times g$ for $5 \mathrm{~min}$ at $4{ }^{\circ} \mathrm{C}$, and the pellet homogenized in NP-40 lysis buffer. Then, cell lysates were rotated for $30 \mathrm{~min}$ at $4{ }^{\circ} \mathrm{C}$, and centrifuged at $16,000 \times g$ for $20 \mathrm{~min}$ at $4^{\circ} \mathrm{C}$. Supernatants were recovered and used as the soluble fractions. To remove carryovers, the pellet was washed with NP-40 lysis buffer and centrifuged again at $16,000 \times g$ for $10 \mathrm{~min}$ at $4{ }^{\circ} \mathrm{C}$. Ureasodium dodecyl sulfate (SDS) buffer composed by $8 \mathrm{M}$ urea and 3\% SDS in NP-40 lysis buffer was used to resuspend the pellet and followed by sonication. Lysates were then spun at $16,000 \times g$ for $20 \mathrm{~min}$ at $4{ }^{\circ} \mathrm{C}$, and the supernatants recovered and used as the detergentinsoluble fractions. To determine protein concentration, the bicinchoninic acid (BCA) assay (Thermo Fisher Scientific) was used, according to the manufacturer's recommendations.

\section{Immunoblot analysis}

Equal amounts of total, insoluble or soluble protein extracts were electrophoretically resolved on $8 \%$ SDSpolyacrylamide gels, and transferred onto nitrocellulose membranes. Then, transient staining with $0.2 \%$ Ponceau $S$ (Merck, Darmstadt, Germany) was used to confirm protein loading and transfer. Following blocking with 5\% milk solution in Tris-buffered saline (TBS), blots were incubated overnight at $4{ }^{\circ} \mathrm{C}$ with primary rabbit polyclonal antibodies reactive to RIP1, RIP3, Akt, p-Akt (Ser473),

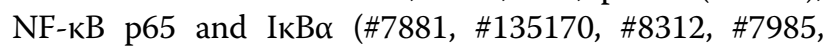
\#372, and \#371; Santa Cruz Biotechnology, Santa Cruz, CA, USA), MLKL (\#M6697; Sigma Aldrich), p-MLKL (Ser358) and p-NF-kB p65 (Ser536) (\#196436, \#131109; Abcam, Cambridge, UK), p-p38 (Thr180/Tyr182) (\#9211; Cell Signaling, Danvers, MA, USA); and with primary mouse monoclonal antibodies reactive to JNK, p-JNK (Thr183/Tyr185),and p38 $\alpha / \beta$ (\#7345, \#6254, \#7972; Santa 
Cruz Biotechnology) and p-IкB $\alpha$ (Ser32/36) (\#9246; Cell Signaling), and finally with secondary goat anti-mouse or anti-rabbit IgG antibody conjugated with horseradish peroxidase (Bio-Rad Laboratories) diluted 1:5000 in blocking solution for $1 \mathrm{~h}$ at room temperature. Membranes were processed for protein detection using Immobilon $^{\mathrm{TM}}$ Western (Merck Millipore, Burlington, MA, USA) or SuperSignal substrate (Pierce, Thermo Fisher Scientific). $\beta$-actin (AC-15; Sigma-Aldrich) was used as endogenous control. Densitometric analysis was performed with the Image Lab Software version 5.1 Beta (Bio-Rad).

\section{Quantitative RT-PCR}

BV2 cells were plated in 12-well plates at $8 \times 10^{5}$ cells/ well for real-time RT-PCR analysis. Briefly, total RNA was extracted using TRIzol ${ }^{\mathrm{Tw}}$ reagent (Invitrogen, Grand Island, USA). RNA was quantified using a $\mathrm{Qubit}^{\mathrm{Tu}} 2.0$ fluorometer (Invitrogen) and then converted into cDNA using NZY Reverse Transcriptase (NZYTech, Lisbon, Portugal). RT-PCR was performed in an Applied Biosystems 7300 System (Thermo Fisher Scientific). The following primer sequences were used: $\mathrm{COX} 2$ gene, $5^{\prime}-\mathrm{C}$ AGCCAGGCAGCAAATCCTT (forward) and 5'-A GTCCGGGTACAGTCACACT (reverse); IL-6 gene, 5'-G ACGATACCACTCCCAACAGACC (forward) and 5'-A AGTGCATCATCGTTGTTCATACA (reverse); NRLP3 gene, 5' -AGAGCCTACAGTTGGGTGAAATG (forward) and $5^{\prime}$-CCACGCCTACCAGGAAATCTC (reverse); and TNF- $\alpha$ gene, 5'-AGGCACTCCCCCAAAAGATG (forward) and 5'-TGAGGGTCTGGGCCATAGAA (reverse). Two independent reactions for each primer set were performed in a total volume of $12.5 \mu \mathrm{l}$ containing $2 \times$ Power SYBR Green PCR master mix (Thermo Fisher Scientific) and $0.3 \mu \mathrm{M}$ of each primer. The relative amounts of each gene transcript were calculated based on the standard curve normalized to the level of hypoxanthine-guanine phosphoribosyltransferase (HPRT) and expressed as fold-change from control cells.

\section{Enzyme-Linked Immunosorbent Assay (ELISA)}

Sandwich ELISA kits (PeproTech) were used to determine TNF- $\alpha$ concentration in culture media. First, the plates were covered with a capture antibody specific for TNF- $\alpha$ overnight at room temperature, followed by removal of the liquid and washing $4 \times$ with washing buffer (0.05\% Tween-20 in PBS). Then, blocking buffer (1\% BSA in PBS) was added for $1 \mathrm{~h}$ at room temperature to block non-specific binding, followed by the same cycle of washes. Afterwards, $100 \mu \mathrm{L}$ of BV2 cell supernatants were added to each well and incubated for $2 \mathrm{~h}$ at room temperature, followed by additional four washes. The detection antibody was then added to each well and incubated for $2 \mathrm{~h}$ at room temperature, followed by four washes as before. Avidin peroxidase was finally incubated during $30 \mathrm{~min}$ at room temperature, followed by four washes as before. Addition of a peroxidase substrate solution then allows the colourless substrate to convert into a soluble blue coloured product. Colour intensity is proportional to the quantity of TNF- $\alpha$ contained in each sandwich structure. Samples were then incubated at room temperature until green colour was visually detectable $( \pm 30 \mathrm{~min})$, followed by absorbance reading at $450 \mathrm{~nm}$, with $590 \mathrm{~nm}$ reference wavelengths using a Bio-Rad Model 680 microplate reader. TNF- $\alpha$ concentration $(\mathrm{pg} / \mathrm{mL})$ was calculated from standard curves.

\section{Immunofluorescence}

NF-KB p65 nuclear translocation in BV2 cells was examined by immunocytochemistry. Briefly, BV2 cells were incubated with zVAD-fmk in the presence or absence of Nec-1 or Oxa12 for $24 \mathrm{~h}$. Then, cells were fixed with $4 \%$ paraformaldehyde in PBS for $20 \mathrm{~min}$ at room temperature, followed by two washes with PBS. Nonspecific binding was blocked with $10 \%$ normal donkey serum for $1 \mathrm{~h}$ at room temperature. Next, cells were incubated with primary mouse monoclonal anti-NF- $\mathrm{kB}$ p65 antibody (1:50, Santa Cruz Biotechnology) overnight at $4{ }^{\circ} \mathrm{C}$. Cells were then washed three times with PBS, followed by incubation with Alexa Fluor 568-conjugated donkey anti-rabbit IgG (1:150, Life Technologies) for $2 \mathrm{~h}$ at room temperature. Nuclei were stained with Hoechst 33258 (Sigma-Aldrich) and mounted on Mowiol mounting medium (Sigma-Aldrich). Images were taken using a fluorescence microscope.

\section{Image analysis}

BV2 and L929 cells morphology was evaluated by phase-contrast microscopy using a Primo Vert microscope and fluorescence images were captured using an Axio ScopeA.1 fluorescent microscope (Carl Zeiss MicroImaging $\mathrm{GmbH}$, Gottingen, Germany). At least 8 images per condition were acquired using an AxioCam 105 Color camera with the Zen lite 2012 (both from Carl Zeiss MicroImaging GmbH). Quantification of p65 NF- $\kappa B$ signal was performed using ImageJ v3.91 software, by selecting a region of interest according to the localization of the nucleus and measurement of fluorescence intensity in the same region.

\section{Statistical analysis}

All data are presented as mean \pm standard error the mean (SEM) of at least three independent experiments. Comparison between groups was made by one-way analysis of variance (ANOVA) followed by post hoc Bonferroni's test. Analysis and graphical presentation were performed with the GraphPad Prism Software 
version 5.00. The statistical significances were achieved when $p<0.05$.

\section{Acknowledgements}

This work was supported by Programme grant SAICTPAC/0019/2015 funded by European Structural and Investment Funds through the COMPETE Programme and by National Funds through Fundação para a Ciência e a Tecnologia (FCT); iMed.ULisboa funded by FCT (UID/DTP/04138/2013); and fellowships funded by FCT (SFRH/BPD/100961/2014, PD/BD/128332/2017, SFRH/BD/102771/2014, and SFRH/BD/110672/2015).

\section{Conflict of interest}

The authors declare that they have no conflict of interest.

\section{Publisher's note}

Springer Nature remains neutral with regard to jurisdictional claims in published maps and institutional affiliations.

The online version of this article (https://doi.org/10.1038/s41420-018-0067-0) contains supplementary material, which is available to authorized users.

Received: 26 March 2018 Revised: 6 May 2018 Accepted: 18 May 2018 Published online: 10 July 2018

\section{References}

1. Miura, M. Active participation of cell death in development and organismal homeostasis. Dev. Growth Differ. 53, 125-136 (2011).

2. Zhou, W. \& Yuan, J. Necroptosis in health and diseases. Semin. Cell. Dev. Biol. 35, 14-23 (2014).

3. Vandenabeele, P., Galluzzi, L., Vanden Berghe, T. \& Kroemer, G. Molecular mechanisms of necroptosis: an ordered cellular explosion. Nat. Rev. Mol. Cell Biol. 11, 700-714 (2010).

4. Kaiser, W. J. et al. Toll-like receptor 3-mediated necrosis via TRIF, RIP3, and MLKL. J. Biol. Chem. 288, 31268-31279 (2013).

5. Schworer, S. A. et al. Toll-like receptor-mediated down-regulation of the deubiquitinase cylindromatosis (CYLD) protects macrophages from necroptosis in wild-derived mice. J. Biol. Chem. 289, 14422-14433 (2014).

6. Li, J. et al. The RIP1/RIP3 necrosome forms a functional amyloid signaling complex required for programmed necrosis. Cell 150, 339-350 (2012).

7. Dondelinger, Y. et al. MLKL compromises plasma membrane integrity by binding to phosphatidylinositol phosphates. Cell Rep. 7, 971-981 (2014).

8. Sun, L. et al. Mixed lineage kinase domain-like protein mediates necrosis signaling downstream of RIP3 kinase. Cell 148, 213-227 (2012).

9. Wang, $\mathrm{H}$. et al. Mixed lineage kinase domain-like protein MLKL causes necrotic membrane disruption upon phosphorylation by RIP3. Mol. Cell 54, 133-146 (2014).

10. Degterev, A. et al. Chemical inhibitor of nonapoptotic cell death with therapeutic potential for ischemic brain injury. Nat. Chem. Biol. 1, 112-119 (2005).

11. He, S. et al. Receptor interacting protein kinase-3 determines cellular necrotic response to TNF-alpha. Cell 137, 1100-1111 (2009).

12. Bonnet, M. C. et al. The adaptor protein FADD protects epidermal keratinocytes from necroptosis in vivo and prevents skin inflammation. Immunity $\mathbf{3 5}$ 572-582 (2011).

13. Afonso, M. B. et al. Necroptosis is a key pathogenic event in human and experimental murine models of non-alcoholic steatohepatitis. Clin. Sci. 129, 721-739 (2015)

14. Re, D. B. et al. Necroptosis drives motor neuron death in models of both sporadic and familial ALS. Neuron 81, 1001-1008 (2014).

15. Ofengeim, D. et al. Activation of necroptosis in multiple sclerosis. Cell Rep. 10, 1836-1849 (2015).

16. Caccamo, A. et al. Necroptosis activation in Alzheimer's disease. Nat. Neurosci. 20, 1236-1246 (2017)

17. lannielli, A. et al. Pharmacological inhibition of necroptosis protects from dopaminergic neuronal cell death in Parkinson's disease models. Cell Rep. 22, 2066-2079 (2018).

18. Mandal, P. et al. RIP3 induces apoptosis independent of pronecrotic kinase activity. Mol. Cel. 56, 481-495 (2014).
19. Fricker, $M$. et al. Caspase inhibitors protect neurons by enabling selective necroptosis of inflamed microglia. J. Biol. Chem. 288, 9145-9152 (2013).

20. Kim, S. \& Li, J. Caspase blockade induces RIP3-mediated programmed necrosis in Toll-like receptor-activated microglia. Cell Death Dis. 4, e716 (2013).

21. Christofferson, D. E. et al. A novel role for RIP1 kinase in mediating TNFalpha production. Cell Death Dis. 3, e320 (2012).

22. Wu, Y. T. et al. ZVAD-induced necroptosis in $L 929$ cells depends on autocrine production of TNFalpha mediated by the PKC-MAPKs-AP-1 pathway. Cell Death Differ. 18, 26-37 (2011).

23. Harris, P. A. et al. Discovery of small molecule RIP1 kinase inhibitors for the treatment of pathologies associated with necroptosis. ACS Med. Chem. Lett. 4 1238-1243 (2013)

24. Moriwaki, K. \& Chan, F. K. RIP3: a molecular switch for necrosis and inflammation. Genes Dev. 27, 1640-1649 (2013).

25. Huang, Z. et al. Necroptosis in microglia contributes to neuroinflammation and retinal degeneration through TLR4 activation. Cell Death Differ. 25, 180-189 (2018).

26. Northington, F. J. et al. Necrostatin decreases oxidative damage, inflammation, and injury after neonatal H. J. Cereb. Blood. Flow. Metab. 31, 178-189 (2011).

27. Liu, T. et al. NF-kB signaling in inflammation. Signal Transduct. Target Ther. $\mathbf{2}$ 17023 (2017).

28. GBD 2015 Neurological Disorders Collaborator Group. Global, regional, and national burden of neurological disorders during 1990-2015: a systematic analysis for the Global Burden of Disease Study 2015. Lancet Neurol. 16, 877-897 (2017)

29. Xu, X. et al. Necrostatin-1 protects against glutamate-induced glutathione depletion and caspase-independent cell death in HT-22 cells. J. Neurochem. 103, 2004-2014 (2007).

30. Rubio-Perez, J. M. \& Morillas-Ruiz, J. M. A review: inflammatory process in Alzheimer's disease, role of cytokines. ScientificWorldJournal 2012, 756357 (2012).

31. Chen, $X$. et al. Translocation of mixed lineage kinase domain-like protein to plasma membrane leads to necrotic cell death. Cell Res. 24, 105-121 (2014).

32. Teng, $X$. et al. Structure-activity relationship study of novel necroptosis inhibitors. Bioorg. Med. Chem. Lett. 15, 5039-5044 (2005).

33. Takahashi, N. et al. Necrostatin-1 analogues: critical issues on the specificity, activity and in vivo use in experimental disease models. Cell Death Dis. 3, e437 (2012).

34. Vandenabeele, P. et al. Necrostatin-1 blocks both RIPK1 and IDO: consequences for the study of cell death in experimental disease models. Cell Death Differ. 20, 185-187 (2013).

35. Hitomi, J. et al. Identification of a molecular signaling network that regulates a cellular necrotic cell death pathway. Cell 135, 1311-1323 (2008).

36. Abderrazak, A. et al. NLRP3 inflammasome: from a danger signal sensor to a regulatory node of oxidative stress and inflammatory diseases. Redox Biol. $\mathbf{4}$ 296-307 (2015).

37. Latz, E., Xiao, T. S. \& Stutz, A. Activation and regulation of the inflammasomes. Nat. Rev. Immunol. 13, 397-411 (2013).

38. Jie, $\mathrm{H}$. et al. Necrostatin-1 enhances the resolution of inflammation by specifically inducing neutrophil apoptosis. Oncotarget 7, 19367-19381 (2016).

39. Hashimoto, Y. et al. Involvement of c-Jun N-terminal kinase in amyloid precursor protein-mediated neuronal cell death. J. Neurochem. 84, 864-877 (2003).

40. Rawal, N. et al. Inhibition of JNK increases survival of transplanted dopamine neurons in Parkinsonian rats. Cell Death Differ. 14, 381-383 (2007).

41. Tortarolo, M. et al. Persistent activation of p38 mitogen-activated protein kinase in a mouse model of familial amyotrophic lateral sclerosis correlates with disease progression. Mol. Cell. Neurosci. 23, 180-192 (2003).

42. Rickle, A. et al. Akt activity in Alzheimer's disease and other neurodegenerative disorders. Neuroreport 15, 955-959 (2004).

43. $\mathrm{Wu}, \mathrm{Y}$. T. et al. Activation of the PI3K-Akt-mTOR signaling pathway promotes necrotic cell death via suppression of autophagy. Autophagy 5, 824-834 (2009).

44. Ye, Y. C. et al. TNFalpha-induced necroptosis and autophagy via supression of the p38-NF-kappaB survival pathway in L929 cells. J. Pharmacol. Sci. 117, 160-169 (2011)

45. Dhillon, A. S. et al. MAP kinase signalling pathways in cancer. Oncogene $\mathbf{2 6}$ 3279-3290 (2007).

46. Liu, Q. et al. Akt and mTOR mediate programmed necrosis in neurons. Cell Death Dis. 5, e1084 (2014). 
47. Jin, S. et al. Metabolic catastrophe as a means to cancer cell death. J. Cell. Sci. 120, 379-383 (2007).

48. McNamara, C. R. et al. Akt Regulates TNFalpha synthesis downstream of RIP1 kinase activation during necroptosis. PLOS ONE 8, e56576 (2013).

49. Camandola, S. \& Mattson, M. P. NF-kappa B as a therapeutic target in neurodegenerative diseases. Expert. Opin. Ther. Targets 11, 123-132 (2007).
50. Pasparakis, M. \& Vandenabeele, P. Necroptosis and its role in inflammation. Nature 517, 311-320 (2015).

51. Rodrigues, C. A. B. et al. Two-photon absorption properties of push-pull oxazolones derivatives. Dyes Pigments 95, 713-722 (2012).

52. Rodrigues, C. A. B. et al. Unsaturated oxazolones as nonlinear fluorophores. Dyes Pigments 99, 642-652 (2013). 